[Contribution fRom the John Harrison Laboratory of Chemistry, No. 8n.]

\title{
COMPLEX THIOSULPHATES.
}

By OWEN LOUIS SHINN.

(Crystallography by Amos P. Brown and Charles Travis.)

Receired June $x_{4}, 1904$.

(A) CUPROUS-SODIUM-AMMONIUM THIOSULPHATE.

WHE.S a concentrated solution of sodium thiosulphate is added to an ammoniacal solution of a copper salt and the mixture allowed to stand for a short time, a mass of deep blue crystals separates. These crystals are stable in the air, are soluble in ammonia, but are decomposed by water. Upon analysis they show the presence of sodium, copper, thiosulphuric acid and ammonia. It was found impossible to completely purify the salt, as even the ammoniacal solution decomposes on standing. The material used for analysis was recrystallized once from ammonia. The results of the analysis were rather confusing, a total of over IOI per cent. being obtained, although they were concordant. The search for an explanation of this yielded a rather surprising fact, irz., the copper was present in the cuprous and not in the cupric condition. This, however, was found difficult to demonstrate in a quantitative way. It was thought that ordinary oxidizing agents, like potassium permanganate or hydrogen peroxide, could be used to oxidize the cuprous oxide and the quantity thus determined. This, however, was not the case, the great readiness with which the solution of this salt absorbs oxygen from the air rendering any quantitative work in that line of no value. Duplicate samples, treated as nearly as possible in the same way, gave results differing by several per cent. It was found, however, that if the finely ground salt be quickly dissolved in ammonia, the solution just decolorized with dilute sulphuric acid and ammonium thiocyanate added, that a white precipitate of cuprous thiocyanate is thrown out and the supernatant liquid gave no reaction for copper with potassium ferrocyanide. Any interruption in this process which permitted oxidation produced a filtrate which gave the characteristic red color of cupric ferrocyanicle.

Various attempts were made to determine the copper by the thiocyanate method without the use of reducing agents, but again results were obtained which varied greatly, the fact being noted that the longer the operation took the lower the percentage of 
copper in the cuprous conlition. A synthesis was then tried. Cuprous oxicle was made by relucing Fehling solution by grapesugar and, after thoroughly washing, was clissolved in ammonia. The solution thus oljtaned, which was almost colorless, was treaterl with a boiled solution of solium thiosuphate and allowed to stand over night in a closed flasl: the next morning the lipuid was still almost coloriess, but a crop of the blue crystals were in the botton of the flask. This was lookel upon as reasonable grouncls for assuming all the copper to be in the lower state of oxiclation and leads to the presentation of the formula

$$
\mathrm{Cu}_{1,} \mathrm{Na}_{8}\left(\mathrm{NH}_{4}\right)_{2} \mathrm{~S}_{1 ;} \mathrm{O}_{22}, \mathrm{ON}^{\top} \mathrm{H}_{3} \text {, }
$$

or

$$
\left.3 \mathrm{Cu}_{2} \mathrm{~S}_{2} \mathrm{O} \mathrm{O}_{3} \cdot 4 \mathrm{Na}_{2} \mathrm{~S}_{2} \mathrm{O}, 3 .\left(\mathrm{NH}_{4}\right)_{2} \mathrm{~S}_{2} \mathrm{O}\right)_{3}, 6 \mathrm{NH}_{3} .
$$

\begin{tabular}{|c|c|c|c|c|c|c|}
\hline 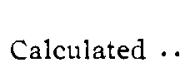 & $\begin{array}{l}\mathrm{Cu}_{2} \mathrm{O} . \\
2 \epsilon .69\end{array}$ & $\begin{array}{l}\mathrm{Na} a_{2} \mathrm{O} . \\
\times 5.53\end{array}$ & $\begin{array}{l}\mathrm{S}_{2} \mathrm{O}_{2} \\
48 . \mathrm{I} 2\end{array}$ & $\begin{array}{l}\mathrm{NH}_{3} \\
\mathrm{~S} .53\end{array}$ & $\begin{array}{l}\mathrm{H}_{2} \mathrm{O} . \\
\mathrm{I} .12\end{array}$ & $\begin{array}{l}\text { Total. } \\
99.98\end{array}$ \\
\hline 01 & $26.5 \mathrm{I}$ & I5.50 & 47.66 & 8.66 & $\ldots$ & 98.33 \\
\hline
\end{tabular}

The analytical results are:

Schutte ${ }^{1}$ and Peltzer" have each made this salt previously; they claim, however, that the copper is present in both conditions of oxidation, but both state that "great difficulty was experienced in cletermining the exact state of oxidation of the copper." Peltzer writes the formula $\mathrm{Cu}_{2} \mathrm{~S}_{2} \mathrm{O}_{3} \cdot \mathrm{CuS}_{2} \mathrm{O}_{3}, 2 \mathrm{Na}_{2} \mathrm{~S}_{2} \mathrm{O}_{3} \cdot 2 \mathrm{NH}_{3}$ without giving any reasons for the assumption that the cuprous and cupric oxicles are to each other as $\mathrm{I}: \mathrm{I}$.

Schutte does not claim an exact ratio and writes the formula

$$
\mathrm{Na}_{2} \mathrm{~S}_{2} \mathrm{O}_{3}\left(\begin{array}{l}
\mathrm{Cu}_{2}^{\prime} \\
\mathrm{Cu}^{\prime \prime}
\end{array}\right) \mathrm{S}_{2} \mathrm{O}_{3} \cdot \mathrm{NH}_{3} \text {. }
$$

He claims that it alepenis upon the conditions just what the relations between the two oxides of copper will be.

In view of the thiocyanate reaction and the synthesis from cuprous oxide it would seem as though these formulas could not be accepted, but that a true cuprous salt is formed, the solution of which readily oxillizes in the air and that both Schutte and Peltzer worked with partially oxidized material.

This salt crystallizes in small needles, which belong to the tetragonal system. It has a rich blue color and, when dry, is fairly stable in the air. When it is adcled to water, a turbid solution

1 Compt. Rend.. 42, 1267.

:Ann. Chem. (Liebig), 126,325 and 128,$15 ;$. 
results, due to a partial decomposition. Ammonia will dissolve it to a blue colored solution, which, upon standing, will deposit black copper sulphide. Dilute sulphuric acid or acetic acid will dissolve it to a colorless solution, which will give strong cupric reactions after standing for a short time. As Peltzer has described, the salt has a decidedly sweet taste and explodes when rubbed with potassium chlorate.

\section{(B) CUPROUS-SODIUM-SILVER THIOSULPHATE.}

When a solution of sodium thiosulphate is added to an ammoniacal solution of a mixture of silver and copper salts, deep blue crystals form after standing for a short time. The crystals of this salt are larger and darker than those of the salt just described. It is not as stable as the copper salt, while it is soluble in ammonia, a crystallization was impossible. When this solution is allowed to stand for a short time silver sulphide will be precipitated. This salt seems to have a definite composition, as varying mixtures of copper and silver gave the same salt as determined by analysis. The difficulty experienced in determining the state of oxidation of the copper in the other salt was encountered here. The same tests which caused the copper to be regarded as cuprous in the other case gave similar results here. The formula may be written,

$$
\mathrm{Cu}_{2} \mathrm{Ag}_{4} \mathrm{Na}_{10} \mathrm{~S}_{14} \mathrm{O}_{24} 6 \mathrm{NH}_{3}
$$

or

$$
\mathrm{Cu}_{2} \mathrm{~S}_{2} \mathrm{O}_{3} .2 \mathrm{Ag}_{2} \mathrm{~S}_{2} \mathrm{O}_{3} \cdot 5 \mathrm{Na}_{2} \mathrm{~S}_{2} \mathrm{O}_{3} \cdot 6 \mathrm{NH}_{3}
$$

Results of analysis

$\begin{array}{lcccccc} & \mathrm{Cu}_{2} \mathrm{O} . & \mathrm{Ag}_{2} \mathrm{O} . & \mathrm{Na}_{2} \mathrm{O} . & \mathrm{S}_{2} \mathrm{O}_{2} . & \mathrm{NH}_{3} . & \text { Total. } \\ \text { Calculated . } & 7.93 & 26.14 & \mathrm{I} 7.3 \mathrm{I} & 42.90 & 5.68 & 99.96 \\ \text { Found } \ldots . . & 8.59 & 25.7 \mathrm{I} & 17.28 & 43.10 & 5.30 & 99.98\end{array}$

The rather large variation in the observed results from those calculated is due to the fact that the salts cannot even be washed to purify them and consequently are contaminated by motherliquor, which is of an indefinite composition, depending upon the mixture taken. These crystals, upon exposure to the light, darken, as most silver salts do. When first made they have a deep blue zolor and are translucent; upon standing, even in a closed bottle, 
they become opaque and lose their blue color. They are finely crystallized in the tetragonal system. 'This salt also has a sweet taste and will explode when rubbed with potassium clilorate.

It was tried to form corresponding salts with all metals which form ammoniacal solutions, but without success in any case. Thi again would indicate that only univalent metals can cnter into this combination. Heltzer, ${ }^{1}$ in rescribing the other salt, states that iron, zine and silver may be substituted for the cuprous copper, but he does not describe the bodies formed. No body containing zinc or iron could be made during the course of these experiments. These compounds serve to bring copper into closer relationship with the other members of the first group of the periodic system

\section{CRYSTALLOGRAPHY.}

As noted in the general description above, the cuprous-silversodium-sulphate. $\mathrm{Cu}_{2} \mathrm{Ag}_{4} \mathrm{Na}_{10} \mathrm{~S}_{10} \mathrm{O}_{24} 6 \mathrm{NH}_{3}$, is obtained in considerably larger crystals than the cuprous-sodium-ammonium-thiosulphate, $\mathrm{Cu}_{6} \mathrm{Na}_{8}\left(\mathrm{NH}_{4}\right)_{2} \mathrm{~S}_{16} \mathrm{O}_{24} 6 . \mathrm{NH}_{3}$, and our crystallographic investigation has been confined principally to this first salt. The crystals of the copper-ammonium salt are too small to be measured on the reflecting goniometer. Approximate measurements by visual reflections and by the microscope indicate, however, the substantial isomorphism of these two salts, and their optical characters, so far as they were determined, are identical. The crystals of the copper-silver salt are very perfect in appearance and some of them were found that gave good images on the goniometer, These were carefully measured with the following results:

Cuprous-sodium-silver-thiosulphate. Tetragonal-pyramidal, group 8 of Dana.

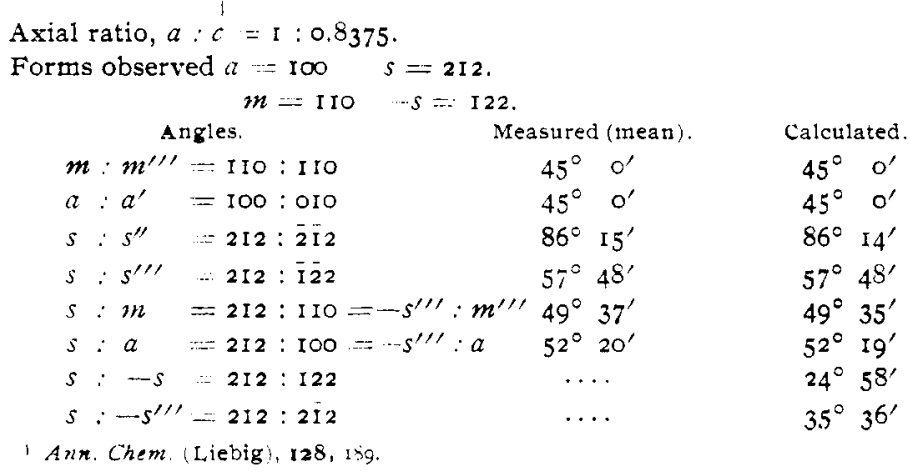


The crystals, Figs. I and 2, are prismatic in habit, the unit

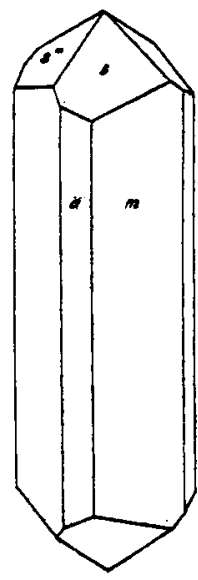

Fig. I.

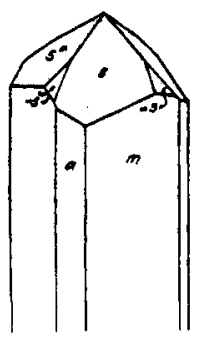

Fig. 2.

prism $m$ (IIO) and the prism of the second order, $a$ (100), being often equally developed; and they are terminated by the third order pyramid, $s(212)$, Fig. I, and occasionally show $-s(222)$ along with the pyramid s(2I2), Fig. 2. The pyramidal planes are usually smooth and give sharp reflections on the goniometer; the prism planes are often striated longitudinally and also diagonally, parallel to the edge $s: m$; and these striations, when present, interfere with good measurement. The measurement on the pyramidal planes, however, was very satisfactory, and the axial ratio determination is practically correct to four places of decimals. No measurements between the plus and the minus third order pyramid faces were made, but the calculated angles are given.

Upon breaking the crystals an imperfect cleavage parallel to the basal pinacoid was observed. No traces of other cleavages were seen.

By transmitted light, deep cobalt-blue. Dichroic: pale saphireblue for light vibrating $\| c(=\varepsilon)$; in thin crystals this is nearly colorless; deep cobalt-blue for light vibrating $\perp c(=\omega)$. Crosssections are opaque unless very thin, when they transmit a deep cobalt-blue color by the ordinary ray. Absorption, $\omega>\varepsilon$. Extinction is straight; in very thin cross-section $\perp \mathcal{L}^{\prime}$ a dusky cross 
is seen in convergent light, indicating the uniaxial character. Optically negative as shown by quartz wedge. etc. Satisfactory measurements of the refractive indices were not obtained, but approximate determinations by the microscope method indicated that $\varepsilon$ was about I.7.

The cuprous-sodium-ammonium-thiosulphate appears to be isomorphous with the silver salt, but the small size of the crystals prevented exact measurement upon the reflecting goniometer, except by visual reflection. The few angles thus obtained (the prismatic zone) showed the tetragonal character. The habit of the crystals is identical with that of the silver salts, the third order pyramid terminating the combination of the unit and second order prisms. By using the microscope the plane angie between the prism edge and the pyramid-prism edge was measured for both salts and found to correspond within a degree.

The optical characters of the copper-sodinm-ammonium salt are identical with those of the silver salt, except that the absorption is stronger in the case of the former. No section that would show the interference figure was obtained with this salt, but it is optically negative, as shown by quartz. wedge.

[CONTRIBUTION FROM THE HAVEMEYER LABORATORIES OF COLUMBIA

UNITERSITY No. IOO.]

\section{CHANGES IN THE COMPOSITION OF SOME FERRO- CYANIDES OF CADMIUM, AND ZINC AFTER PRECIPITATION. ${ }^{1}$}

BX EDMCND H. Miller and M. J, Falk.

Receired June 23, 1904.

Ix 1897 , in discussing ${ }^{2}$ two papers read before the New York Section on the "Ferrocyanides of Zinc and of Manganese," the suggestion was made that these complicated precipitates could all be resolved into two ferrocyanides having simple ratios, i. e., $\mathrm{RK}_{2} \mathrm{Fe}(\mathrm{CN})_{6}$ and $\mathrm{R}_{2} \mathrm{Fe}(\mathrm{CN})_{6}$, where $\mathrm{R}$ is a dyad metal. This idea was advanced as the alternative to stipplying elaborate formulae to the precipitates formed, in order to satisfy the iron-manganese and iron-zinc ratios found by analysis.

1 Read at the Providence meeting of the Americat Chemical society.

2 Discussion by Miller: This Journal, 19, 556 (1997). 